\title{
Hepatocyte growth factor ameliorates mucosal injuries leading to inhibition of colon cancer development in mice
}

\author{
NAOHISA YAMAJI ${ }^{1,2}$, AKIO IDO $^{1,2}$, AKIHIRO MORIUCHI $^{1,2}$, MASATSUGU NUMATA ${ }^{1,2}$, \\ HITOSHI SETOYAMA $^{1,2}$, TSUTOMU TAMAI ${ }^{2}$, KEITA FUNAKAWA ${ }^{2}$, HIROSHI FUJTA ${ }^{2}$, \\ TOSHIO SAKIYAMA ${ }^{2}$, HIROFUMI UTO ${ }^{2}$, MAKOTO OKETANI ${ }^{2}$ and HIROHITO TSUBOUCHI ${ }^{1,2}$
}

${ }^{1}$ HGF Hepatic Regeneration Therapy Project, Department of Experimental Therapeutics, Translational Research Center, Kyoto University Hospital, Sakyo-ku, Kyoto 606-8507; ${ }^{2}$ Digestive Disease and Life-Style Related Disease, Kagoshima University Graduate School of Medical and Dental Sciences, Kagoshima 880-8520, Japan

Received February 24, 2011; Accepted April 8, 2011

DOI: 10.3892/or.2011.1294

\begin{abstract}
Hepatocyte growth factor (HGF), which facilitates the repair of injured mucosa, has the potential to be a new therapeutic agent for inflammatory bowel disease (IBD). However, given that the incidence of colorectal cancer increases continuously with disease duration in patients with IBD, the fact that HGF is a potent mitogen for intestinal epithelial cells may further heighten the risk of bowel cancer in this patient population. In this study, we examined the effects of recombinant HGF on colorectal cancer development in mice with or without experimentally induced colitis. Although HGF stimulated proliferation of colonic epithelial cells in normal mucosa, the development of colorectal cancer induced by repeated injection of azoxymethane (AOM) was significantly inhibited by HGF treatment. In a mouse model of colitis-associated cancer, colorectal cancer frequently developed despite only a single injection of AOM prior to three cycles of dextran sulfate sodium administration. However, HGF treatment significantly facilitated the repair of injured mucosa, leading to inhibition of colorectal cancer development in a dose-dependent manner. Thus, HGF-induced repair of injured mucosa inhibits rather than accelerates the development of colorectal cancer, and these results also suggest the importance of blocking the cycles of mucosal injury and repair to prevent colitis-associated colorectal cancer.
\end{abstract}

\section{Introduction}

Inflammatory bowel disease (IBD), such as ulcerative colitis and Crohn's disease, is an intractable disease characterized by chronic relapsing inflammation of the gastrointestinal tract.

Correspondence to: Dr Akio Ido, Digestive Disease and Life-Style Related Disease, Kagoshima University Graduate School of Medical and Dental Sciences, 8-35-1 Sakuragaoka, Kagoshima 880-8520, Japan E-mail: ido-akio@m2.kufm.kagoshima-u.ac.jp

Key words: hepatocyte growth factor, colorectal cancer, colitisassociated cancer, mucosal injury, carcinogenesis
The primary therapies for IBD are anti-inflammatory and anti-immune agents, such as salazosulfapyridine, mesalazine, corticosteroids, mercaptopurine, azathioprine, methotrexate and cyclosporine $(1,2)$. Recently, a chimeric mouse-human monoclonal antibody against tumor necrosis factor (TNF)- $\alpha$ was shown to be extremely effective in Crohn's disease $(3,4)$, and another calcineurin inhibitor, tacrolimus, was effective in the treatment of IBD (5). However, side effects associated with these medications were frequently noted and colitis was often recurrent and intractable in spite of the therapy, leading not only to cessation of these agents but also to impaired quality of life.

Hepatocyte growth factor (HGF) was first purified as a potent hepatocyte mitogen from the plasma of patients with fulminant hepatic failure (6). This protein functions as a mitogen, motogen and morphogen for multiple subsets of epithelial cells, including those of the gastrointestinal tract (6-8). HGF activator and HGF activator inhibitor type-1, both HGF-associated molecules involved in the activation of HGF in injured tissues, are associated with colonic mucosal repair $(9,10)$; HGF expression is increased in inflamed colonic mucosal tissues in patients with ulcerative colitis (11). We previously reported that systemic administration of recombinant human HGF ameliorated experimental colitis in rats $(12,13)$. Perturbed homeostasis between luminal antigens (e.g., commensal bacteria) and mucosal immunity serves as a critical determinant in the development of gut inflammation in IBD. Therefore, treatment that enhances the remodeling and repair of injured mucosa may be essential for the treatment of IBD; this approach may ultimately prove to be more successful than either anti-inflammatory or anti-immune therapy. However, the evident mitogenic activity of HGF has the potential to increase the risk of cancer development; and in patients with IBD, particularly those with ulcerative colitis, the risk of colorectal cancer continuously increases with the duration of the disease $(14,15)$. In fact, recent investigations have reported that the cumulative risk for colorectal cancer ranges between $10-18 \%$ in patients with a disease history of 30 or more years $(16,17)$, and that colitis-associated colorectal cancer is responsible for $10-15 \%$ of all deaths in UC patients (18). In this context, before clinical applications of recombinant 
A

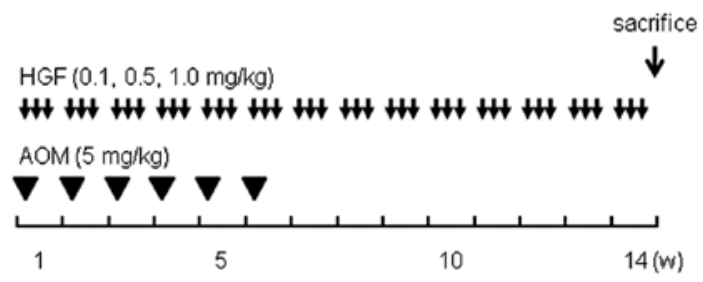

B

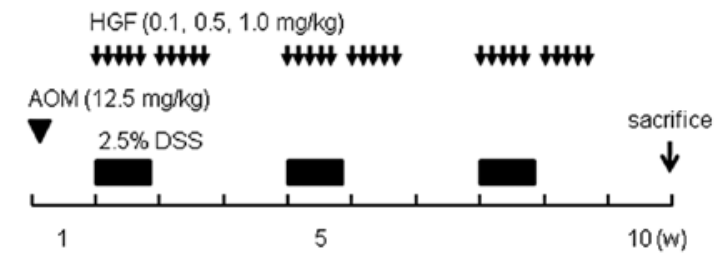

Figure 1. Animal models of colorectal cancer and HGF administration. (A) To induce AOM-induced colorectal cancer, mice received intraperitoneal injections of AOM $(5 \mathrm{mg} / \mathrm{kg})$ once a week for 6 weeks. Recombinant HGF $(0.1,0.5$ or $1.0 \mathrm{mg} / \mathrm{kg} /$ day $)$ or vehicle control were intraperitoneally administered every second day for 14 weeks. (B) Colitis-associated colorectal cancer was induced in mice by a single injection of AOM (12.5 mg) followed by three cycles of $2.5 \%$ DSS, where each cycle consisted of 5 days of DSS treatment followed by 16 days of regular water. Intraperitoneal injections of recombinant HGF or vehicle control were initiated with the DSS treatment, and continued for 2 weeks ( 5 days a week) in each cycle.

HGF to treat IBD patients are developed, it must first be ascertained, whether repeated doses of recombinant HGF increase the risk of accelerating the development of colorectal cancer, particularly colitis-associated colorectal cancer, and second, whether HGF-induced enhanced repair of injured mucosa leads to prevention of colitis-associated colorectal cancer. In this study, we examined the effect of repeated injections of recombinant HGF on the development of colorectal cancer in mice with or without repeated mucosal injury.

\section{Materials and methods}

Animals. Male A/J mice, 7 weeks of age, and female CBA/J mice, 5 weeks of age, were obtained from Japan SLC (Shizuoka, Japan). The animals were maintained under constant room temperature $\left(25^{\circ} \mathrm{C}\right)$ and given free access to water and a standard diet throughout the study. The protocol for animal studies was approved by the Ethics Committee of the Graduate School of Medicine, Kyoto University. All animal experiments were performed after a 1-week acclimation period.

Animal models of colon cancer and recombinant human (rh)-HGF administration. To assess the effects of HGF on colon tumor development, A/J mice, 8 weeks of age and weighing between 22 and $23 \mathrm{~g}$, were injected intraperitoneally with azoxymethane (AOM) (5 mg/kg) (Sigma-Aldrich, St. Louis, MO, USA) once a week for 6 weeks (Fig. 1A). Intraperitoneal injections of rh-HGF $(0.1,0.5$ or $1.0 \mathrm{mg} / \mathrm{kg} /$ day) or phosphate-buffered saline (PBS) were initiated with the AOM injection and were continued every second day for 14 weeks. The number, incidence and multiplicity of colon tumors were determined after the 14-week HGF regimen was complete. To induce colitis-related cancer, $\mathrm{CBA} / \mathrm{J}$ mice, 7 weeks of age and weighing $\sim 19 \mathrm{~g}$, were injected with a single dose of AOM $(12.5 \mathrm{mg} / \mathrm{kg})$ followed by three cycles of $2.5 \%$ dextran sulfate sodium (DSS) adminis-tration, in which each cycle consisted of 5 days of DSS treatment followed by 16 days of regular water (Fig. 1B). Intraperitoneal injections of HGF or PBS were initiated with the DSS treatment, and were continued for 2 weeks ( 5 days a week) in each cycle. Two weeks after the final administration of DSS, the number, incidence and multiplicity of colon tumors were examined. To evaluate the severity of DSS-induced colitis, the disease activity index (DAI) was assessed during the first cycle of DSS and HGF administration.

Histological examination. The entire colon was excised postmortem and fixed with $10 \%$ formalin for histological analysis. The longitudinal sections were embedded in paraffin and stained with hematoxylin and eosin (H\&E). The sections were assessed according to diagnostic criteria for gastrointestinal carcinomas independently by two investigators blinded to the experimental protocol (19). Colon tumors falling under category 4, including high-grade adenoma/dysplasia, suspected carcinoma and mucosal carcinoma, were defined as colorectal cancers. The number of colorectal tumors was scored to determine the incidence (number of animals with at least one tumor) and multiplicity (number of tumors per animal) of neoplasms.

To evaluate the degree of DSS-induced colitis, all colonic tissues were obtained after the first cycle of HGF or PBS administration, fixed with $10 \%$ formalin and stained with $H \& E$. Histological scoring was assessed independently by three investigators blinded to the experimental protocol, and was expressed as a combined score of inflammatory cell infiltration (0-3) and tissue damage (0-3) (20). For inflammatory cell infiltration, the presence of rare inflammatory cells in the lamina propria was scored as 0 , increased number of inflammatory cells in the lamina propria as 1 , confluence of inflammatory cells extending into the submucosa as 2, and transmural extension of the inflammatory cell infiltrate as 3 . For epithelial damage, absence of mucosal damage was scored as 0 , discrete focal lymphoepithelial lesions were counted as 1 , mucosal erosion or ulceration as 2 , and extensive mucosal damage and extension through deeper structures of the bowel wall as 3 . The two subscores were added, and the combined histological score ranged from 0 (no change) to 6 (extensive cell infiltration and tissue damage).

Immunohistochemistry. To evaluate the proliferation of the colonic epithelium, cells undergoing proliferation were identified by immunohistochemistry for Ki-67 using antimouse Ki-67 monoclonal antibody (MIB-5) (DakoCytomation, Copenhagen, Denmark). Following visualization of the Ki-67 antigen, the number of Ki-67-positive cells in 10 crypts was counted under a microscope at $\mathrm{x} 400$ magnification in the normal mucosa and in the colon tumors independently by three investigators blinded to the experimental protocol.

Statistical analysis. Unless otherwise specified, data are expressed as the mean \pm SD. Statistical parameters were ascertained with Statview J-4.5 software (Abacus Concept, 

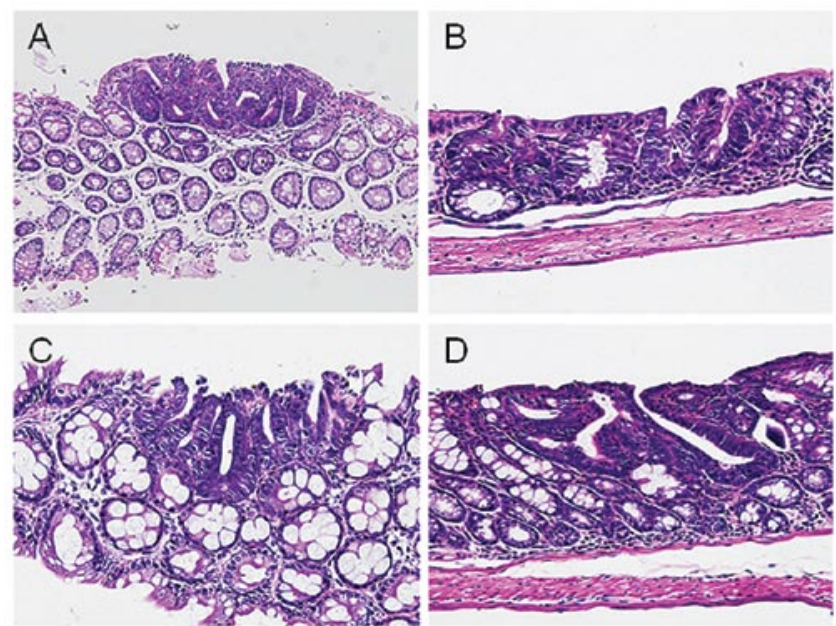

Figure 2. Representative microscopic appearance of AOM-induced colorectal cancer developing in mice treated with or without HGF. All colorectal cancers developing in AOM-treated mice were identified as intramucosal carcinomas. There was no apparent difference in the microscopic appearance of the colorectal cancers between mice treated with vehicle control (A) or $\mathrm{HGF}$ at a dose of 0.1 (B), 0.5 (C) or $1.0 \mathrm{mg} / \mathrm{kg}$ (D) (magnification x100).

Berkeley, CA). The differences between means were compared using the Mann-Whitney $U$ test. Values of $\mathrm{p}<0.05$ were considered statistically significant.

\section{Results}

Repeated intraperitoneal injection of HGF inhibits development of colorectal cancer in mice treated with AOM. First, we examined the effect of repeated doses of HGF on AOM-induced colorectal cancer. Pathologically, all colorectal cancers that developed in the AOM-treated mice were identified as intramucosal carcinomas. There was no apparent difference in the microscopic appearance of the colorectal cancers between mice treated with the vehicle control and $\operatorname{HGF}(0.1,0.5$ and $1.0 \mathrm{mg} / \mathrm{kg}$ ) (Fig. 2). However, the development of colorectal cancer was significantly inhibited in mice treated with HGF at each dose ( $\mathrm{p}=0.02$ for each) (Table I). The incidence and multiplicity of the tumors also decreased in the mice treated with HGF at each dose, and both were significantly inhibited by 1.0 and $0.1 \mathrm{mg} / \mathrm{kg}$ of HGF administration ( $\mathrm{p}=0.04$ and 0.03 , respectively).
A
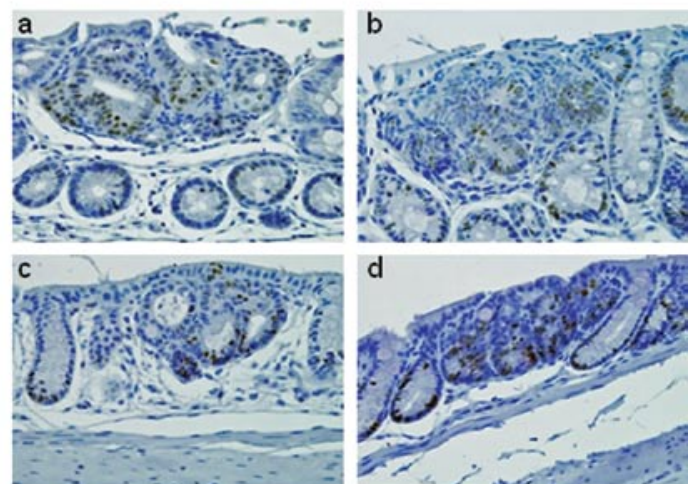

B

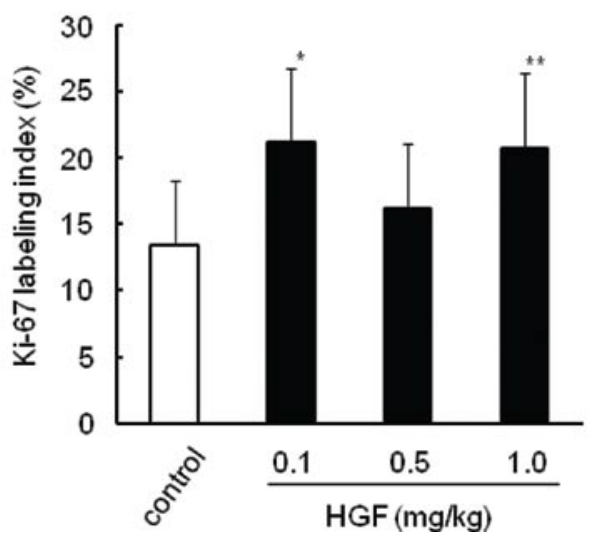

Figure 3. Repeated intraperitoneal injections of HGF stimulates the proliferation of colonic epithelial cells in normal mucosa. The proliferation of colonic epithelial cells was examined by immunohistochemistry using antimouse Ki-67 monoclonal antibody. (A) Ki-67-positive cells were observed in both cancerous and non-cancerous colon tissues in AOM-treated mice receiving vehicle control (a) or HGF at a dose of 0.1 (b), 0.5 (c) or $1.0 \mathrm{mg}$ / $\mathrm{kg}$ (d). (B) The Ki-67 labeling index (the number of Ki-67-positive epithelial cells in 10 crypts) in normal, non-cancerous colonic mucosa increased in mice treated with HGF; repeated administration of HGF at a dose of 0.1 or $1.0 \mathrm{mg} / \mathrm{kg}$ significantly stimulated the proliferation of colonic epithelial cells. ${ }^{*} \mathrm{p}=0.001$ and ${ }^{* *} \mathrm{p}=0.002$ vs. vehicle control.

HGF administration stimulates the proliferation of epithelial cells in normal colonic mucosa. Since HGF is a potent mitogen for intestinal epithelial cells, we determine whether HGF stimulated cell proliferation of colonic mucosa using immuno-

Table I. Repeated doses of HGF inhibit development of AOM-induced colon cancer.

\begin{tabular}{|c|c|c|c|c|}
\hline & \multicolumn{2}{|c|}{ No. of tumors } & \multirow[b]{2}{*}{ Tumor incidence } & \multirow[b]{2}{*}{ Tumor multiplicity } \\
\hline & Total & Mean \pm SD & & \\
\hline Vehicle control $(n=20)$ & 40 & $2.00 \pm 2.22$ & 0.65 & 3.08 \\
\hline \multicolumn{5}{|l|}{ HGF } \\
\hline $0.1 \mathrm{mg} / \mathrm{kg}(\mathrm{n}=14)$ & 6 & $0.43 \pm 0.65^{\mathrm{a}}$ & 0.36 & $1.20^{\mathrm{c}}$ \\
\hline $0.5 \mathrm{mg} / \mathrm{kg}(\mathrm{n}=13)$ & 5 & $0.38 \pm 0.65^{\mathrm{a}}$ & 0.31 & 1.25 \\
\hline $1.0 \mathrm{mg} / \mathrm{kg}(\mathrm{n}=14)$ & 6 & $0.43 \pm 0.76^{\mathrm{a}}$ & $0.29^{b}$ & 1.50 \\
\hline
\end{tabular}

Tumor incidence was compared by Fisher's exact test, and other parameters were compared by the Mann-Whitney U test. ${ }^{\mathrm{a}} \mathrm{p}=0.02$, ${ }^{\mathrm{b}} \mathrm{p}=0.04$ and ${ }_{\mathrm{c}}^{\mathrm{p}}=0.03$, compared with vehicle control. 
A

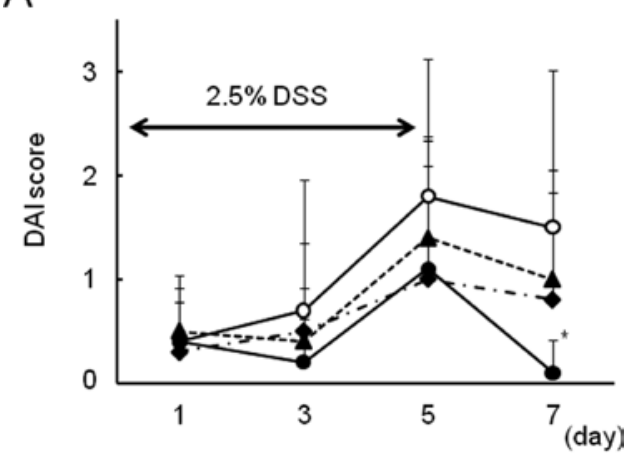

B

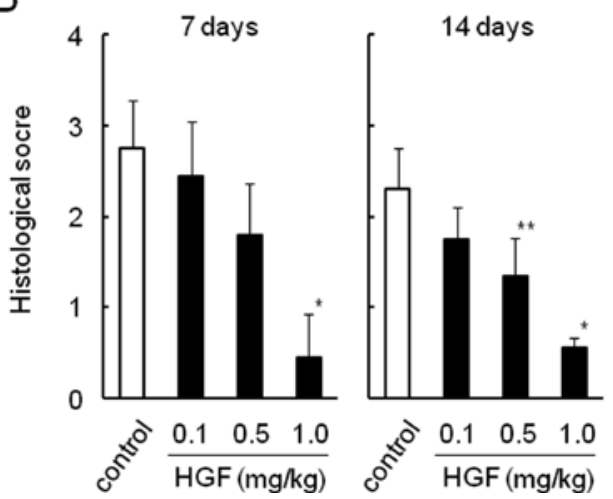

Figure 4. Repeated doses of HGF ameliorated DSS-induced colitis. (A) Mice were treated with vehicle control (O) or HGF at a dose of $0.1(\mathbf{\Delta}), 0.5(\bullet)$, or $1.0 \mathrm{mg} / \mathrm{kg}(\bullet)$ for seven days. Treatment with $\mathrm{HGF}$ at a dose of $1.0 \mathrm{mg} / \mathrm{kg}$ significantly decreased DAI scores in comparison with mice treated with vehicle control ( $\mathrm{p}=0.02$ vs. vehicle control). (B) Repeated HGF doses of 0.5 and $1.0 \mathrm{mg} / \mathrm{kg}$ significantly improved the histological score $(" \mathrm{p}=0.03$ and ** $\mathrm{p}=0.045$ vs. vehicle control).

histochemistry for Ki-67. Colonic epithelial cells positive for $\mathrm{Ki}-67$ were observed in both cancerous and non-cancerous colon tissues (Fig. 3A). Repeated doses of HGF markedly inhibited the development of AOM-induced colorectal cancer (Table I), and the resulting small number of tumors in the HGF-treated mice prevented us from being able to quantify the Ki-67-positive cells in colorectal cancer. However, the $\mathrm{Ki}-67$ labeling index in normal, non-cancerous mucosa significantly increased in mice treated with 0.1 and $1.0 \mathrm{mg} / \mathrm{kg}$ of HGF ( $\mathrm{p}=0.001$ and 0.002 , respectively) (Fig. 3B).
Repeated doses of HGF inhibits development of AOM-induced colorectal cancer in mice with experimental colitis. Before investigating the effects of HGF on the development of colitisassociated colorectal cancer, the degree of DSS-induced colitis in mice treated with or without HGF was evaluated. Mice administered 2.5\% DSS for 5 days, which were treated with vehicle control, exhibited only mild mucosal injury with low DAI $(<2)$ and histological scores (<3) (Fig. 4). Repeated doses of HGF ameliorated DSS-induced colitis in a dose-dependent manner. HGF administration at a dose of $1.0 \mathrm{mg} / \mathrm{kg}$ for 7 days significantly reduced both DAI and histological scores $(\mathrm{p}=0.02$ and 0.03 , respectively), and 0.5 and $1.0 \mathrm{mg} / \mathrm{kg}$ of $\mathrm{HGF}$ administered for 14 days also significantly improved histological scores ( $p=0.045$ and 0.03 , respectively) (Fig. 4).

To examine the effect of repeated doses of HGF on colitisassociated colorectal cancer, mice were administered a single injection of AOM, followed by three cycles of 1-week $2.5 \%$ DSS dosing and 2-week cessation and simultaneous treatment with HGF $(0.1,0.5$ and $1.0 \mathrm{mg} / \mathrm{kg}$ ) or vehicle control for 2 weeks (Fig. 1B). Repeated doses of HGF suppressed the number, incidence and multiplicity of colorectal cancers in a dose-dependent manner; treatment with $1.0 \mathrm{mg} / \mathrm{kg}$ of HGF significantly reduced the number and multiplicity of colitisassociated colorectal cancers ( $\mathrm{p}=0.01$ and 0.02 , respectively) (Table II). Pathologically, all colorectal cancers were identified as intramucosal carcinomas, and there was no difference in microscopic appearance between mice treated with vehicle control and HGF (Fig. 5). We evaluated the epithelial cell proliferation in colitis-associated colorectal cancers and normal, non-cancerous, mucosas 7 days after the third HGF treatment. Although the Ki-67 labeling index in colorectal cancers was significantly increased in comparison with normal, noncancerous mucosa $(\mathrm{p}=0.03)$, there was no significant difference in cell proliferation in both the cancerous and non-cancerous colon tissues between AOM/DSS-treated mice receiving vehicle control and HGF (Fig. 6).

\section{Discussion}

HGF is a multifunctional polypeptide produced by mesenchymal cells and functions as a mitogen, morphogen and/or motogen for multiple subsets of epithelial cells. HGF has the potential to be a novel therapeutic agent for intractable diseases of various organs, including the liver $(21,22)$, nervous system $(23)$, lung

Table II. Repeated doses of HGF inhibit development of colitis-associated colon cancer.

\begin{tabular}{lcccc}
\hline & \multicolumn{2}{c}{ No. of tumors } & & \\
\cline { 2 - 3 } & Total & Mean $\pm \mathrm{SD}$ & Tumor incidence & Tumor multiplicity \\
\hline Vehicle control $(\mathrm{n}=10)$ & 66 & $6.60 \pm 5.27$ & 0.90 & 7.33 \\
HGF & 66 & $6.60 \pm 4.99$ & 1.00 & 6.60 \\
$0.1 \mathrm{mg} / \mathrm{kg}(\mathrm{n}=10)$ & 37 & $3.70 \pm 1.95$ & 0.90 & 4.11 \\
$0.5 \mathrm{mg} / \mathrm{kg}(\mathrm{n}=10)$ & 16 & $1.60 \pm 1.51^{\mathrm{a}}$ & 0.60 & $2.67^{\mathrm{b}}$ \\
$1.0 \mathrm{mg} / \mathrm{kg}(\mathrm{n}=10)$ & & & & \\
\hline
\end{tabular}

Tumor incidence was compared by the Fisher's exact test, and other parameters were compared by the Mann-Whitney $\mathrm{U}$ test. ${ }^{\mathrm{a}} \mathrm{p}=0.01$ and ${ }^{\mathrm{b}} \mathrm{p}=0.02$, compared with vehicle control. 
A

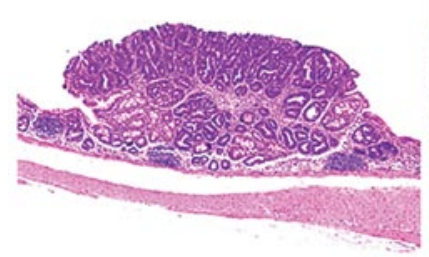

C

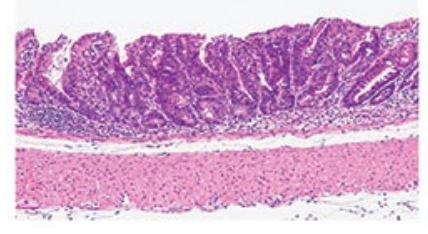

B

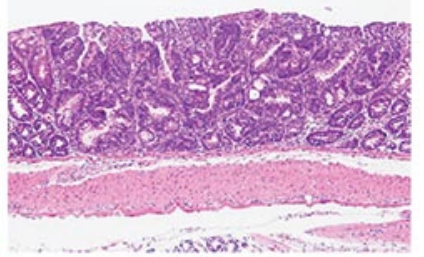

D

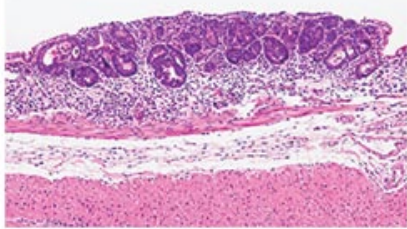

Figure 5. Representative microscopic appearance of colitis-associated colorectal cancer developing in AOM/DSS-treated mice. All colitis-associated colorectal cancers were identified as intramucosal carcinomas. There was no apparent difference in the microscopic appearance of colorectal cancers between AOM/DSS-treated mice receiving vehicle control (A) or HGF at a dose of 0.1 (B), 0.5 (C) or $1.0 \mathrm{mg} / \mathrm{kg}$ (D) (magnification x100).

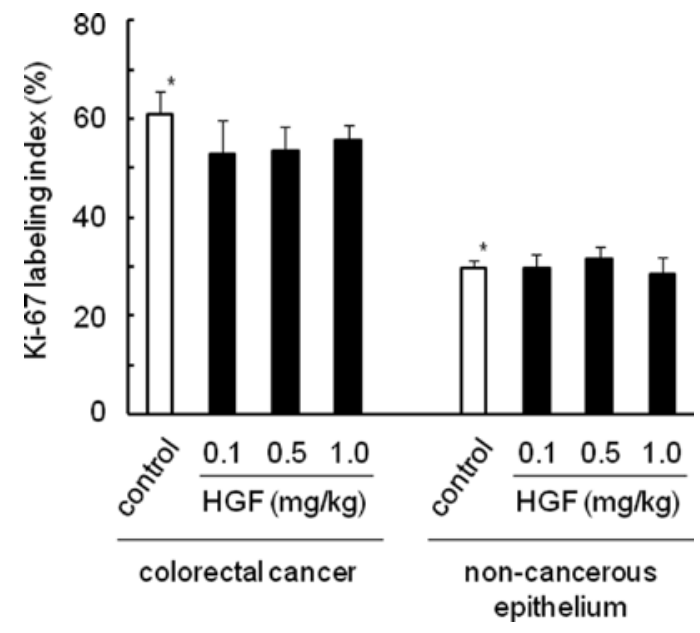

Figure 6 . The proliferation of colonic epithelial cells was not persistently stimulated by repeated doses of recombinant HGF in mice with AOM/DSSinduced colorectal cancer. The Ki-67 labeling index in colitis-associated colorectal cancer and normal mucosa was examined in mice treated with AOM/DSS 7 days after the third HGF treatment. Although cell proliferation was significantly stimulated in colorectal cancer in comparison with noncancerous mucosa ( $\mathrm{p}=0.03)$, there was no significant difference in the Ki-67 labeling index in cancerous and non-cancerous tissues between mice treated with vehicle control or HGF.

(24), heart (25) and kidney (26). We therefore developed translational medicine protocols for recombinant human HGF, including preparation of a GMP-grade compound, various preclinical safety tests, and a phase I/II clinical trial to evaluate the safety, pharmacokinetics and clinical efficacy of recombinant human HGF in patients with fulminant hepatitis (27). Since HGF is a potent mitogen for hepatocytes, we confirmed before initiating a human trial that repeated doses of intravenous HGF did not accelerate the development of hepatocellular carcinoma in rats fed a choline-deficient, L-amino acid-defined diet (28). We recently reported that treatment with recombinant
HGF stimulates the repair of injured intestinal mucosa, leading to amelioration of experimental colitis $(12,13)$. However, repeated doses of HGF may exhibit oncogenic potential; therefore the carcinogenic potential of HGF should be evaluated as precisely as possible before clinical applications of this agent.

In the present study, we first examined the effects of repeated HGF dosing on AOM-induced colorectal cancer in mice without colitis, and showed that HGF treatment significantly inhibited the development of colorectal cancer in normal mucosa despite stimulation of epithelial cell proliferation. Recent investigations found that HGF prevented intestinal epithelial cells from apoptosis $(29,30)$. HGF is thought to interact with c-Met, a specific receptor for HGF that is expressed on the basolateral membranes of epithelial cells (31); recombinant HGF administered intraperitoneally stimulated the proliferation of epithelial cells in colonic mucosa through an increase in serum HGF concentration (12). HGF/c-Met signaling has been reported to have both positive and negative effects on carcinogenesis. In cell culture studies, HGF can either increase cell survival (32-34) or inhibit cell growth and induce apoptosis in a variety of cancer cell lines (35-37). In transgenic mice expressing HGF, various types of tumors developed, including liver, breast, skin and muscle (38-40). In contrast, transgenic mice expressing HGF under control of the albumin promoter did not form liver tumors (41), and transgenic coexpression with HGF suppressed both c-Myc- (42) and transforming growth factor (TGF)- $\alpha$-driven (43) hepatocarcinogenesis. Conversely, increased MET signaling in early-stage colorectal cancer is a common occurrence, and elevated MET expression or amplification in advanced disease is linked to metastatic progression $(44,45)$. However, cancer cells with increased MET expression lack autocrine HGF production (46), suggesting that the receptor exists in a ligand-independent active conformation. Additionally, the loss of c-Met signaling in hepatocytes enhanced rather than suppressed the earlystage chemical hepatocarcinogenesis $(47,48)$. Therefore, the net outcome of HGF/c-Met activation in normal intestinal epithelial cells is phenotypically different from the effect on colorectal cancer cells, and does not necessarily lead to the enhanced development of colorectal cancer.

In AOM/DSS-treated mice, although mice administered 2.5\% DSS exhibited mild colonic mucosal injury, enhanced development of colorectal cancer was observed in comparison with mice treated with a repeated injection of AOM alone (Tables I and II). Changes in TGF- $\beta$ signaling or activation of the intrinsic tyrosine kinase of the EGF receptor while stimulating the synthesis of TGF- $\alpha$ have been reported to contribute to tumor development in mice treated with $\mathrm{AOM}$ (49-51). However, despite a single injection of AOM before DSS administration, repeated mucosal injury and repair facilitated the development of colorectal cancer, demonstrating the strong association between chronic mucosal inflammation and colorectal cancer. Although the molecular nature of this connection is largely unknown, the importance of inflammation is highlighted by the dependence of tumor growth and progression on the canonical activation of nuclear factor

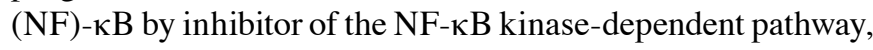
which is crucial for tumor growth and progression (52). Additionally, recent investigations suggest that mechanisms include chronic formation of reactive oxygen species (53) and 
tumorigenesis induced by chronic epithelial exposure or inflammatory stimuli, such as interleukin- 6 and tumor necrosis factor- $\alpha$ (54-57). Thus, the close link between chronic inflammation and colorectal cancer also suggests that therapeutic modalities blocking the cycles of mucosal injury and repair possibly contribute to prevention of colitis-associated colorectal cancer. We showed here that repeated doses of HGF significantly facilitated the repair of injured mucosa in AOM/ DSS-treated mice (Fig. 4), and consequently inhibited the development of colitis-associated colorectal cancer (Table II). Although HGF ameliorates mucosal injury through its mitogenic and anti-apoptotic effects on colonic epithelial cells $(12,13,30)$, improvement of the microenvironment, which means the reduction of chronic epithelial exposure to proinflammatory cytokines, growth factors and reactive oxygen species throughout repeated cycles of mucosal injury and repair, is considered to be a primary contributor to the prevention of colitis-associated colorectal cancer.

The effectiveness and impact of HGF on various intractable diseases have been extensively investigated primarily using in vivo $\mathrm{HGF}$ gene transfer or HGF transgenic mice that led to persistent exposure to HGF (23-25). We showed here that there was no significant difference in epithelial cell proliferation in the colonic mucosa of AOM/DSS-treated mice after repeated HGF administration (Fig. 6). These findings seem reasonable due to the short half-life of recombinant HGF (58). Therefore, from the standpoint of carcinogenic risk, treatment with recombinant HGF can provide a higher level of safety than HGF gene therapy.

This study demonstrated that repeated doses of recombinant HGF significantly inhibited AOM-induced colorectal cancer despite its stimulatory effect on colonic epithelial cell proliferation, and efficiently attenuated colonic mucosal injury, leading to prevention of colitis-associated colorectal cancer. HGF/c-Met activation has been reported to result in both activation and inhibition of carcinogenesis, and therefore this issue should be addressed more extensively. However, the inhibitory effect of recombinant HGF on the development of colorectal cancer, particularly in mice with repeated mucosal injury, offers a significant contribution towards a novel therapeutic approach that facilitates the repair of injured mucosa, which differs from existing anti-inflammatory and anti-immune therapies.

\section{Acknowledgements}

The authors thank Ms. Sayoko Ohara and Ms. Yuko MorinagaNakamura for the technical assistance. This study was supported by funds from the Ministry of Education, Culture, Sports, Science and Technology of Japan.

\section{References}

1. Hanauer SB and Present DH: The state of the art in the management of inflammatory bowel disease. Rev Gastroenterol Disord 3: 81-92, 2003.

2. Nguyen GC, Harris ML and Dassopoulos T: Insights in immunomodulatory therapies for ulcerative colitis and Crohn's disease. Curr Gastroenterol Rep 8: 499-501, 2006.

3. Sandborn WJ and Hanauer SB: Antitumor necrosis factor therapy for inflammatory bowel disease: a review of agents, pharmacology, clinical results, and safety. Inflamm Bowel Dis 5: 119-133, 1999.
4. Colombel JF, Sandborn WJ, Reinisch W, Mantzaris GJ, Kornbluth A, Rachmilewitz D, Lichtier S, D'Haens G, Diamond RH, Broussard DL, Tang KL, van der Woude CJ and Rutgeerts P; SONIC Study Group: Infliximab, azathioprine, or combination therapy for Crohn's disease. N Eng J Med 362: 1383-1395, 2010.

5. Baumgart DC, Pintoffl JP, Sturm A, Wiedenmann B and Dignass AU: Tacrolimus is safe and effective in patients with severe steroid-refractory or steroid-dependent inflammatory bowel disease - a long-term follow-up. Am J Gastroenterol 101: 1048-1056, 2006.

6. Gohda E, Tsubouchi H, Nakayama H, Hirono S, Sakiyama O, Takahashi K, Miyazaki H, Hashimoto S and Daikuhara Y: Purification and partial characterization of hepatocyte growth factor from plasma of a patient with fulminant hepatic failure. J Clin Invest 81: 414-419, 1988

7. Joplin R, Hishida T, Tsubouchi H, Daikuhara Y, Ayres R, Neuberger JM and Strain AJ: Human intrahepatic biliary epithelial cells proliferate in vitro in response to human hepatocyte growth factor. J Clin Invest 90: 1284-1289, 1992.

8. Takahashi M, Ota S, Terano A, Yoshiura K, Matsumura M, Niwa Y, Kawabe T, Nakamura T and Omata M: Hepatocyte growth factor induces mitogenic reaction to the rabbit gastric epithelial cells in primary culture. Biochem Biophys Res Commun 191: 528-534, 1993.

9. Itoh H, Kataoka H, Tomita M, Hamasuna R, Nawa Y, Kitamura N and Koono M: Upregulation of HGF activator inhibitor type 1 but not type 2 along with regeneration of intestinal mucosa. Am J Physiol Gastrointest Liver Physiol 278: 635-643, 2000.

10. Kataoka H, Shimomura T, Kawaguchi T, Hamasuna R, Itoh H, Kitamura N, Miyazawa K and Koono M: Hepatocyte growth factor activator inhibitor type 1 is a specific cell surface binding protein of hepatocyte growth factor activator (HGFA) and regulates HGFA activity in the pericellular microenvironment. J Biol Chem 275: 40453-40462, 2000.

11. Kitamura S, Kondo S, Shinomura Y, Isozaki K, Kanayama S, Higashimoto Y, Minami T, Kiyohara T, Yasunaga Y, Ishikawa H, Ohtani T, Ishiguro S and Matsuzawa Y: Expression of hepatocyte growth factor and c-met in ulcerative colitis. Inflamm Res 49: 320-324, 2000.

12. Tahara Y, Ido A, Yamamoto S, Miyata Y, Uto H, Hori T, Hayashi K and Tsubouchi H: Hepatocyte growth factor facilitates colonic mucosal repair in experimental ulcerative colitis in rats. J Pharmacol Exp Ther 307: 146-151, 2003.

13. Numata M, Ido A, Moriuchi A, Kim I, Tahara Y, Yamamoto S, Hasuike S, Nagata K, Miyata Y, Uto H and Tsubouchi H: Hepatocyte growth factor facilitates the repair of large colonic ulcers in 2,4,6-trinitrobenzene sulfonic acid-induced colitis in rats. Inflamm Bowel Dis 11: 551-558, 2005.

14. Lakatos PL and Lakatos L: Risk for colorectal cancer in ulcerative colitis: changes, causes and management strategies. World J Gastroenterol 14: 3937-3947, 2008.

15. Zisman TL and Rubin DT: Colorectal cancer and dysplasia in inflammatory bowel disease. World J Gastroenterol 14: 2662-2669, 2008.

16. Rutter MD, Saunders BP, Wilkinson KH, Rumbles S, Schofield G, Kamm MA, Williams CB, Price AB, Talbot IC and Forbes A: Thirty-year analysis of a colonoscopic surveillance program for neoplasia in ulcerative colitis. Gastroenterology 130: 1030-1038, 2006.

17. Eaden JA, Abrams KR and Mayberry JF: The risk of colorectal cancer in ulcerative colitis: a meta-analysis. Gut 48: 526-535, 2001.

18. Munkholm P: The incidence and prevalence of colorectal cancer in inflammatory bowel disease. Alimnet Pharmacol Ther 18: 1-5, 2003.

19. Schlemper RJ, Kato Y and Stolte M: Diagnostic criteria for gastrointestinal carcinomas in Japan and Western countries: proposal for a new classification system of gastrointestinal epithelial neoplasia. J Gastroenterol Hepatol 15: G49-G57, 2000.

20. Siegmund B, Rieder F, Albrich S, Wolf K, Bidlingmaier C, Firestein GS, Boyle D, Lehr HA, Loher F, Hartmann G, Endres S and Eigler A: Adnosine kinase inhibitor GP515 improves experimental colitis in mice. J Pharmacol Exp Ther 296: 99-105, 2001.

21. Kosai K, Matsumoto K, Funakoshi H and Nakamura T: Hepatocyte growth factor prevents endotoxin-induced lethal hepatic failure in mice. Hepatology 30: 151-159, 1999. 
22. Kusumoto K, Ido A, Moriuchi A, Katsura T, Kim ID, Takahama Y, Numata M, Kodama M, Hasuike S, Nagata K, Uto H, Inui K and Tsubouchi H: Repeated intravenous injection of recombinant human hepatocyte growth factor ameliorates liver cirrhosis but causes albuminuria in rats. Int J Mol Med 17: 503-509, 2006.

23. Sun W, Funakoshi $\mathrm{H}$ and Nakamura T: Overexpression of HGF retards disease progression and prolongs life span in a transgenic mouse model of ALS. J Neurosci 22: 6537-6548, 2002.

24. Yaekashiwa M, Nakayama S, Ohnuma K, Sakai T, Abe T, Satoh K, Matsumoto K, Nakamura T, Takahashi T and Nukiwa T: Simultaneous or delayed administration of hepatocyte growth factor equally represses the fibrotic changes in murine lung injury induced by bleomycin. A morphogenic study. Am J Respir Crit Care Med 156: 1937-1944, 1997.

25. Miyagawa S, Sawa Y, Taketani S, Kawaguchi N, Nakamura T, Matsuura $\mathrm{N}$ and Matsuda $\mathrm{H}$ : Myocardial regeneration therapy for heart failure: hepatycte growth factor enhances the effect of cellular cardiomyoplasty. Circulation 105: 2556-2561, 2002.

26. Kawaida K, Matsumoto K, Shimazu H and Nakamura T: Hepatocyte growth factor prevents acute renal failure and accelerates renal regeneration in mice. Proc Natl Acad Sci USA 91: 4357-4361, 1994.

27. Ido A and Tsubouchi H: Translational research to identify clinical applications of hepatocyte growth factor. Hepatol Res 39: 739-747, 2009.

28. Nakanishi C, Moriuchi A, Ido A, Numata M, Kim ID, Kusumoto K, Hasuike S, Abe H, Nagata K, Akiyama Y, Uto H, Kataoka $\mathrm{H}$ and Tsubouchi $\mathrm{H}$ : Effect of hepatocyte growth factor on endogenous hepatocarcinogenesis in rats fed a cholinedeficient, L-amino acid-defined diet. Oncol Rep 16: 25-31, 2006

29. Kuenzler KA, Arthur LG and Schwartz MZ: A possible mechanism for prevention of intestinal programmed cell death after ischemia-reperfusion injury by hepatocyte growth factor pretreatment. J Pediatr Surg 37: 1696-1699, 2002.

30. Ohda Y, Hori K, Tomita T, Hida N, Kosaka T, Fukuda Y, Miwa $\mathrm{H}$ and Matsumoto $\mathrm{T}$ : Effects of hepatocyte growth factor on rat inflammatory bowel disease models. Dig Dis Sci 50 : 914-921, 2005.

31. Nusrat A, Parkos CA, Bacarra AE, Godowski PJ, Delp-Archer C, Rosen EM and Madara JL: Hepatocyte growth factor/scatter factor effects on epithelia. Regulation of intercellular junctions in transformed and non-transformed cell lines, basolateral polarization of c-met receptor in transformed and natural intestinal epithelia, and induction of rapid wound repair in a transformed model epithelium. J Clin Invest 93: 2056-2065, 1994.

32. Miyazaki M, Gohda E, Tsuboi S, Tsubouchi H, Daikkuhara Y, Namba $M$ and Yamamoto I: Human hepatocyte growth factor stimulates the growth of HUH-6 clone 5 human hepatoglastome cells. Cell Biol Int Rep 16: 145-154, 1992

33. Lee HS, Huang AM, Huang GT, Yang PM, Chen PJ, Sheu JC, Lai MY, Lee SC, Chou CK and Chen DS: Hepatocyte growth factor stimulates the growth and activates mitogen-activated protein kinase in human hepatoma cells. J Biomed Sci 5: 180-184, 1998

34. Suzuki A, Hayashida M, Kawano H, Sugimoto K, Nakano T and Shiraki K: Hepatocyte growth factor promotes cell survival from fas-mediated cell death in hepatocellular carcinoma cells via Akt activation and Fas-deth-inducing signaling complex suppression. Hepatology 32: 796-802, 2000.

35. Shiota G, Rhoads DB, Wang TC, Nakamura T and Schimidt EV: Hepatocyte growth factor inhibits growth of hepatocellular carcinoma cells. Proc Natl Acad Sci USA 89: 373-377, 1992.

36. Derksen PW, De Gorter DJ, Meijer HP, Bende RJ, van Dijk M, Lokhorst HM, Bloem AC, Spaargaren M and Pals ST: The hepatocyte growth factor/Met pathway controls proliferation and apoptosis in multiple myeloma. Leukemia 17: 764-774, 2003.

37. Conner EA, Wirht PJ, Kiss A, Santoni-Rugiu E and Thorgeirsson SS: Growth inhibition and induction of apoptosis by HGF in transformed rat liver epithelial cell. Biochem Biophys Res Commun 236: 396-401, 1997.

38. Sakata H, Takayama H, Sharp R, Rubin JS, Merlino G and LaRochelle WJ: Hepatocyte growth factor/scatter factor overexpression induced growth, abnormal development, and tumor formation in transgenic mouse livers. Cell Growth Differ 7: 1513-1523, 1996

39. Takayama H, LaRochelle WJ, Sharp R, Otsuka T, Kriebel P, Anver M, Aaronson SA and Merlino G: Diverse tumorigenesis associated with aberrant development in mice overexpressing hepatocyte growth factor/scatter factor. Proc Natl Acad Sci USA 94: 701-706, 1997
40. Gallego MI, Bierie B and Hennighausen L: Target expression of HGF/SF in mouse mammary epithelium leads to metastatic adenosquamous carcinomas through the activation of multiple signal transduction pathways. Oncogene 22: 8498-8508, 2003.

41. Shiota G, Wang TC, Nakamura TC and Schmidt EV: Hepatocyte growth factor in transgenic mice: effects on hepatocyte growth, liver regeneration and gene expression. Hepatology 19: 962-972, 1994.

42. Santoni-Rugiu E, Preisegger KH, Kiss A, Audolfsson T, Shiota G, Shhmidt EV and Thorgeirsson SS: Inhibition of neoplastic development in the liver by hepatocyte growth factor in a transgenic mouse model. Proc Natl Acad Sci USA 93: 9577-9582, 1996.

43. Shiota G, Kawasaki H, Nakamura T and Schmidt EV: Characterization of double transgenic mice expressing hepatocyte growth factor and transforming growth factor-alpha. Res Commun Mol Pathol Pharmacol 90: 17-24, 1995.

44. Herynk MH, Stoeltzing O, Reinmuth N, Parikh NU, Abounader R, Laterra J, Radinsky R, Ellis LM and Gallick GE: Downregulation of c-Met inhibits growth in the liver human colorectal carcinoma cells. Cancer Res 63: 2990-2996, 2003.

45. Zeng ZS, Weiser MR, Kuntz E, Chen CT, Khan SA, Forslund A, Nash GM, Gimbel M, Yamaguchi Y, Culliford AT IV, D'Alessio M, Barany F and Paty PB: c-Met gene amplification is associated with advanced stage colorectal cancer and liver metastases. Cancer Lett 265: 258-269, 2008.

46. Birchmeier C, Birchmeier W, Gherardi E and van de Wounde GF: Met, metastatasis, motility and more. Nat Rev Mol Cell Biol 4: 915-925, 2003.

47. Takami T, Kaposi-Novak P, Uchida K, Gomez-Quiroz LE, Conner EA, Factor VM and Thorgeirsson SS: Loss of hepatocyte growth factor/c-Met signaling pathway accelerates early stages of N-nitrosodiethylamine-induced hepatocarcinogenesis. Cancer Res 67: 9844-9851, 2007.

48. Marx-Stoelting P, Borowiak M, Knorpp T, Birchmeier C, Buchmann A and Schwarz M: Hepatocarcinogenesis in mice with a conditional knockout of the hepatocyte growth factor receptor c-Met. Int J Cancer 124: 1767-1772, 2009.

49. Guda K, Giardina C, Nambial P, Cui H and Resenberg DW: Aberrant transforming growth factor-beta signaling in azoxymethane-induced mouse colon tumors. Mol Carcinog 31: 204-213, 2001

50. Guda K, Claffey KP, Dong M, Nambiar PR and Rosenberg DW: Defective processing of the transforming growth factor-betal in azoxymethane-induced mouse colon tumors. Mol Carcinog 37: $51-59,2003$

51. Relan NK, Saeed A, Ponduri K, Fligiel SE, Dutta S and Majumdar AP: Identification and evaluation of the role of endogenous tyrosine kinases in azoxymethane induction of proliferative process in the colonic mucosa of rats. Biochim Biophys Acta 1244: 368-376, 1995

52. Greten FR, Eckmann L, Greten TF, Park JM, Li ZW, Egan LJ, Kagnoff MF and Karin M: IKKbeta links inflammation and tumorigenesis in a mouse model of colitis-associated cancer. Cell 118: 285-296, 2004.

53. Coussens LM and Werb Z: Inflammation and cancer. Nature 420: 860-867, 2002.

54. Popivanova BK, Kitamura K, Wu Y, Kondo T, Kagaya T, Kaneko S, Oshima M, Fujii C and Mukaida N: Blocking TNF-alpha in mice reduces colorectal carcinogenesis associated with chronic colitis. J Clin Invest 118: 560-570, 2008.

55. Becker C, Fantini MC, Schramm C, Lehr HA, Wirtz S, Nikolaev A, Burg J, Strand S, Kiesslich R, Huber S, Ito H, Nishimoto N, Yoshizaki K, Kishimoto T, Galle PR, Blessing M, Rose-John S and Neurath MF: TGF-beta suppresses tumor progression in colon cancer by inhibition of IL-6 trans-signaling. Immunity 21: 491-501, 2004.

56. Bollrath J, Phesse TJ, von Burstin VA, Putoczki T, Bennecke M, Bateman T, Nebelsiek T, Lundgren-May T, Canli O, Schwitalla S, Matthews V, Schmid RM, Kirchner T, Arkan MC, Ernst M and Greten FR: gp130-mediated Stat 3 activation in enterocytes regulates cell survival and cell-cycle progression during colitisassociated tumorigenesis. Cancer Cell 15: 91-102, 2009.

57. Grivennikov S, Karin E, Terzic J, Mucida D, Yu GY, Vallabhapurapu S, Scheller J, Rose-John S, Cheroutre H, Eckmann L and Karin M: IL-6 and Stat 3 are required for survival of intestinal epithelial cells and development of colitisassociated cancer. Cancer Cell 15: 103-113, 2009.

58. Ido A, Moriuchi A, Kim Il, Numata M, Nagata-Tsubouchi Y, Hasuike S, Uto H and Tsubouchi H: Pharmacokinetic study of recombinant human hepatocyte growth factor administered in a bolus intravenously or via portal vein. Hepatol Res 30: 175-181, 2004. 